\title{
Selected Abstracts from the 7th Congress Meeting of the Asia Pacific Association of Medical Toxicology
}

Editor's Note: In an effort to promote international poison information sharing, the Journal of Medical Toxicology is publishing selected abstracts from this meeting, held in Chandigarh, India, December 7-10, 2008. The focus of this selection is primarily original research in the area of organophosphate poisoning, something we have much less experience with in the United States. With the increased exposure, along with groundbreaking research on optimal antidotal therapy, these abstracts contain information that could change our practice or give one ideas for future research.

\section{PRALIDOXIME CHLORIDE IN ACUTE ORGANOPHOSPHORUS INSECTICIDE SELF-POISONING: A RANDOMISED PLACEBO-CONTROLLED TRIAL}

\begin{abstract}
M Eddlestona,b,c, P Eyerd, F Woreke, E Juszczakf, N Alderf, F Mohammed b,c, L Senarathnab,c, A Hittarageg, S Azherh, K Jeganathang, S Jayamanneh, L Von Meyeri, AH Dawsonc,j, MHR Sheriffb,c, NA Buckleyc,k

${ }^{a}$ Centre for Tropical Medicine, Nuffield Department of Clinical Medicine, University of Oxford, UK; ${ }^{\mathrm{O}}{ }_{\mathrm{x}-\mathrm{Col}}$ Collaboration, Department of Clinical Medicine, Faculty of Medicine, University of Colombo, Sri Lanka; 'South Asian Clinical Toxicology Research

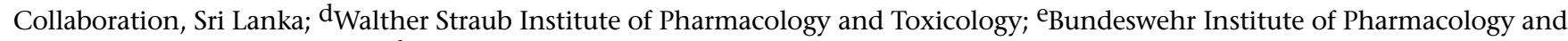
Toxicology, Munich, Germany; ${ }^{\mathrm{f}}$ Centre for Statistics in Medicine, Wolfson College, University of Oxford, England; $\mathrm{g}_{\text {Anuradhapura }}$ General Hospitals, North Central Province, Sri Lanka; hPolonnaruwa General Hospitals, North Central Province, Sri Lanka; Institute of Legal Medicine, Ludwig Maximilians University, Munich, Germany; ISchool of Public Health, University of Newcastle, Australia; kProfessorial Unit, Department of Medicine, University of New South Wales, Sydney, Australia
\end{abstract}

Objective: Poisoning with organophosphorus insecticides is a major global public health problem, causing an estimated 200,000 deaths each year. Although the World Health Organization recommends use of pralidoxime, it remains unclear whether this antidote offers clinical benefit. We aimed to determine whether the addition of pralidoxime chloride to atropine and supportive care offers benefit.

Methods: We performed a double-blind, randomised, placebo-controlled trial of pralidoxime chloride (2-g loading dose over 20 min, followed by $0.5 \mathrm{~g} / \mathrm{hr}$ for up to 7 days) versus saline. Mortality was the primary outcome; secondary outcomes included intubation, duration of intubation, and time to death.

Results: 235 patients were randomised to receive pralidoxime (121) or saline placebo (114). Mortality was nonsignificantly higher in patients receiving pralidoxime: 30/121 (24.8\%) receiving pralidoxime died, compared with 18/114 (15.8\%) receiving placebo (adjusted hazard ratio $1.69,95 \% \mathrm{CI} 0.88-3.26, \mathrm{P}=0.12$ ). The need for intubation was similar in both groups (pralidoxime $26 / 121$ [21.5\%] vs. placebo 24/114 [21.1\%], adjusted hazard ratio 1.27 [95\% CI 0.71-2.29]). To reduce confounding due to ingestion of different insecticides, we further analysed patients with confirmed chlorpyrifos or dimethoate poisoning alone, finding no evidence of benefit. The RCT was registered as ISRCTN55264358.

Conclusion: Despite significant reactivation of AChE, we found no evidence that this pralidoxime regimen improves survival or reduces need for intubation and intensive care in organophosphorus pesticide-poisoned patients. The reason for this failure to benefit patients was not apparent from the study. Further studies of different dose regimens or different oximes are required.

\section{TOXICODYNAMICS OF CHLORPYRIFOS AND THE EFFECT OF PRALIDOXIME}

DM Robertsa,b,c, P Eyerd, AH Dawsona,c,e, M Fahima,e, M Eddlestona,c,f, NA Buckleya,b,c,e

aSouth Asian Clinical Toxicology Research Collaboration; ${ }^{b}$ Australian National University, Australia; ${ }^{C}$ University of Colombo, Sri Lanka; dLudwig Maximilians University, Germany; eUniversity of Peradeniya, Sri Lanka; fScottish Poisons Information Bureau, UK

Introduction: Pralidoxime (PAM) is a reactivator of chlorpyrifos-inhibited AChE, but the regimen that maximally reactivates AChE and prevents aging (irreversible inhibition) has not been confirmed in controlled clinical studies. The effect of PAM on the time course of erythrocyte-AChE inhibition in patients with acute chlorpyrifos poisoning was determined. 
Methods: Patients received resuscitation and titrated dosing of atropine on admission to hospital. Each was administered one of three PAM regimens: $1 \mathrm{~g}$ every six hours for up to 48 hours (Group A), 2-g bolus then $0.5 \mathrm{~g} /$ hr by infusion until recovery (Group B), or placebo (normal saline, Group C). Serial blood samples were obtained for quantification of PAM concentration and AChE activity (both active [in vivo] and re-activatable [in vitro or nonaged, after addition of a supratherapeutic concentration-100 $\mu \mathrm{M}-$ of obidoxime ex vivo]). Data were pooled to determine the PAM plasma profile and the plateau in vitro AChE activity as a measure of the extent of aging. The percentage of active AChE at discharge was determined by comparing the in vivo to in vitro AChE activity of individuals in each group.

Results: The mean plateau PAM plasma concentration was $84.6 \mu \mathrm{M}$ (95\% CI 68.8-100.4 $\mu \mathrm{M})$ in Group B compared to $12.6 \mu \mathrm{M}$ (95\% CI 0.0 to $27.56 \mu \mathrm{M})$ in Group A. Changes in AChE activities during admission for each group are described in Table 1 . PAM minimised the degree of aging, particularly at higher doses where aging appeared to occur for a short time only. There was a higher proportion of active in vivo AChE in Group B than others at discharge, yet there were two deaths in each group.

Table 1: Changes in AChE activities during admission

\begin{tabular}{|c|c|c|c|}
\hline Treatment & 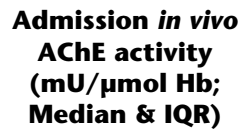 & $\begin{array}{c}\text { Decrease in in vitro } \\
\text { AChE activity } \\
\text { during admission } \\
(\mathbf{m U} / \mu \mathrm{mol} \mathrm{Hb} ; \text { mean } \pm \mathrm{SD})\end{array}$ & $\begin{array}{c}\text { Percentage of AChE } \\
\text { that is active } \\
\text { at discharge } \\
(\% \text {; median } \pm \text { SD) }\end{array}$ \\
\hline Group A $(n=24)$ & $69(33-114)^{\ddagger}$ & $106 \pm 153^{*, 5}$ & $57.4 \pm 37.5^{\#, @}$ \\
\hline Group B $(n=21)$ & $50(32-73)^{\circ}$ & $43 \pm 142^{*}$ & $77.0 \pm 28.2^{\#}$ \\
\hline Group C $(n=14)$ & $40(25-49)$ & $319 \pm 83^{s}$ & $15.2 \pm 15.9^{@}$ \\
\hline
\end{tabular}

Conclusions: PAM reactivates chlorpyrifos-induced AChE inhibition in a dose-dependent manner. The clinical benefits of PAM in acute chlorpyrifos poisoning remains to be confirmed.

\section{REGENERATION OF RED CELL CHOLINESTERASE ACTIVITY FOLLOWING PRALIDOXIME (2-PAM) INFUSION IN FIRST 24 HOURS IN ORGANOPHOSPHATE- POISONED PATIENTS}

PGN Guptab, S Singha, A Bhalla ${ }^{a}$, N Sharma $a, K D$ Gill $b$

a Department of Biochemistry and Internal Medicine, Postgraduate Institute of Medical Education and Research, Chandigarh160012 (India); b Postgraduate Institute of Medical Education and Research, Chandigarh- 160012 (India)

Background: Oximes such as pralidoxime chloride reactivate acetylcholinesterase. However, their role in the management of organophosphate poisoning is controversial.

Objectives: The study was carried out to find effectiveness of pralidoxime chloride (2-PAM) in regenerating red cell acetyl cholinesterase in the first 24 hours following administration of it in doses recommended by the World Health Organisation.

Patients and Methods: Eight patients with OPP [chlorpyriphos (3), phorate (3), dichlorvos (1) and monocrotophos (1)] who fulfilled the criteria for inclusion were investigated. In addition to decontamination and atropine, all these patients were administered $30 \mathrm{mg} / \mathrm{kg}$ body weight of 2-PAM as bolous dose followed by $7.5 \mathrm{mg} / \mathrm{kg}$ body weight/hr with maximum dose being $500 \mathrm{mg} / \mathrm{hr}$ as continuous infusion for the first 24 hours. Red cell AChE activity was estimated every 15 minutes for the first 4 hours, 1 hourly for the next 4 hours and then 2 hourly for 24 hours and subsequently without 2-PAM every 12 hours for 7 days or discharge or death, whichever came first.

Results: In all the patients maximum increase in activity was observed in the first 4 hours, following which rise was very slow despite continued 2-PAM infusion and reaching a steady state in 20 hours in all the cases. The increase in red cell AChE activity observed in the diethyl group at 24 hours of 2-PAM infusion was $154 \%$ vs. $81 \%$ in the dimethyl group. At 7 days the increase in activity was $215 \%$ vs. $118 \%$, respectively. However, on multiple repeated ANOVA, no statistically significant difference was observed between diethyl and dimethyl groups at admission and discharge $(\mathrm{p}>0.05)$. Similarly, no significant difference was observed in three groups when patients were categorized according to WHO classification of organophosphates $(\mathrm{p}>0.05)$.

Conclusion: The maximum increase in red cell AChE activity occurs in the first 4 hours of 2-PAM administration followed by a slow increase despite 2-PAM infusion for 24 hours. 


\title{
POTASSIUM HOMEOSTASIS IN PATIENTS WITH ACUTE ORGANOPHOSPHORUS POISONING
}

\author{
IB Gawarammana ${ }^{a}$, KS Kularathnab ${ }^{b}$ AH Dawson ${ }^{a}$
}

aSouth Asian Clinical Toxicology Research Collaboration, Faculty of Medicine, University of Peradeniya, Sri Lanka; ${ }^{b}$ Toxicology Unit, Teaching Hospital, Peradeniya Sri Lanka

Introduction: Although only $2 \%$ of total body potassium (70-100 mEq) remains in the extracellular compartment, it plays a critical role in maintaining cell membrane resting potential (RMP). Relatively small changes in extracellular potassium concentration can significantly alter RMP and functional activity of electrically excitable cells. Hypokalaemia was noted on admission in 5/60 patients with organophosphate poisoning [1]. This phenomenon may compound the weakness due to inhibition of acetylcholine esterase by organophosphorus compounds (OP). $\mathrm{K}$ is tightly balanced in that urinary $\mathrm{K}$ excretion $(1-1.5 \mathrm{mmol} / \mathrm{kg} / \mathrm{day})$ is directly proportional to the total body potassium and is a good marker of total body $\mathrm{K}$.

Methods: We prospectively measured serum K and urinary potassium excretion on days 1 to 3 in consenting patients following ingestion of OP.

Results: There were 35 patients (median age 45 years-IQR 24-45, 18 males) in acute cholinergic phase; $41 \%$ ingested chlorpyrifos (Table 1). Median serum $\mathrm{K}$ remained in the lower range of normal. $\mathrm{K}$ excretion was lower than average, $1 \mathrm{mmol} / \mathrm{kg} / \mathrm{day}$ on day 1 . There was a significant reduction in median $\mathrm{K}$ excretion on day $2(\mathrm{p}=0.004)$, which did not differ between OP type and gender.

Table 1:

\begin{tabular}{lccc}
\hline & Day 1 & Day 2 & Day 3 \\
\hline $\begin{array}{l}\text { Serum K [median and IQR (mmol/L)] } \\
\text { Urinary K excretion [median and }\end{array}$ & $3.6(3.2-3.8)$ & $3.8(3.4-4)$ & $3.6(3.2-4)$ \\
IQR (mmol/Kg/day)] & $0.8(0.3-1)$ & $0.2(0.1-0.6)$ & $0.45(0.28-0.7)$ \\
\hline
\end{tabular}

Discussion: Potassium homeostasis appears to be altered in acute organophosphate poisoning, with evidence suggesting renal conservation of potassium. Potential causes include intracellular shift, poor intake, gastrointestinal loss, and changes in aldosterone and cortisol levels. It is possible that alterations in $\mathrm{K}$ may alter neuromuscular junction function in OP-poisoned patients or alter cardiac conduction and contribute to overall mortality and morbidity.

Conclusion: Patients with OP poisoning seem to conserve excretion of $\mathrm{K}$ to maintain normal serum $\mathrm{K}$ even on day 1 , which reached a maximum on day 2. Further studies should be done to investigate the causes of this phenomenon and the effect of routine $\mathrm{K}$ replacement to $\mathrm{K}$ excretion and RMP.

Reference:

1. Mahdi Balali-Mood et al., Use of high doses of sodium bicarbonate in acute organophosphorous pesticide poisoning is advancing. Clin Toxicol 2007;45(1):92.

\section{PREDICTORS OF SUCCESSFUL EXTUBATION AND VENTILATORY OUTCOME IN ORGANOPHOSPHATE POISONING}

\author{
BMGD Yasaratne ${ }^{a, b}$, IB Gawarammana, $a$, CDA Goonasekarac, KS Kularatned, AH Dawson ${ }^{b}$ \\ aProfessorial Medical Unit, Teaching Hospital, Peradeniya, Sri Lanka; bSouth Asian Clinical Toxicology Research Collaboration, \\ Faculty of Medicine, University of Peradeniya, Sri Lanka; ${ }^{C}$ Department of Anaesthesiology, Faculty of Medicine, University of

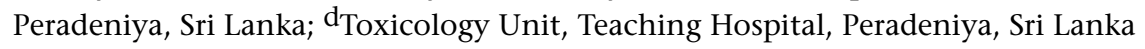

Objective: To find out clinical predictors of successful extubation following mechanical ventilation after organophosphate (OP) poisoning.

Methods: We prospectively observed neck muscle power before extubation, requirement of atropine within 24 hours prior to extubation, oropharyngeal suction frequency within 4 hours after extubation, peak expiratory flow rate (PEFR) within 12 hours after extubation, presence of lung infection, and rates of reintubation within 72 hours of extubation. The investigators were not involved in decision making on extubation. 


\begin{tabular}{lcccc}
\hline Table 1: Outcome in Organophosphate-Induced Respiratory Failure & \\
\hline $\begin{array}{l}\text { Type of } \\
\text { Organophosphate }\end{array}$ & $\begin{array}{c}\text { Number of } \\
\text { admissions }\end{array}$ & $\begin{array}{c}\text { Number } \\
\text { ventilated }\end{array}$ & $\begin{array}{c}\text { Number of } \\
\text { reintubations }\end{array}$ & $\begin{array}{c}\text { Number of } \\
\text { deaths }\end{array}$ \\
\hline Chlorpyriphos & 30 & 15 & 4 & 4 \\
\hline Dimethoate & 22 & 7 & 0 & 2 \\
\hline Profenophos & 8 & 3 & 2 & 1 \\
\hline Fenthion & 3 & 3 & 0 & 0 \\
\hline Malathion & 1 & 1 & 1 & 1 \\
\hline Diazinon & 1 & 1 & 0 & 1 \\
\hline Other & 9 & 4 & 2 & 0 \\
\hline Unidentified & 20 & 9 & 1 & 2 \\
\hline Total & 94 & 43 & 10 & 11 \\
\hline
\end{tabular}

Results: Forty-three patients (32 males, 11 females; age range 13-77 years) were ventilated following OP at Toxicology Unit, Teaching Hospital, Peradeniya, during the study period of 12 months. Reintubation was observed in ten (23.3\%), while eleven (25.6\%) succumbed to the illness (Table 1). Lower rates of reintubation was associated with neck muscle power of 4 or more (Medical Research Council scale; odds ratio 15.2, 95\% confidence interval 2.4-95.0, p < 0.05), nonrequirement of atropine within 24 hours prior to extubation (OR 7.3, 95\% CI 1.3-41.0, p < 0.05), nonrequirement of more than two oropharyngeal suctions within 4 hours of extubation (OR 28, 95\% CI 3.9-199, p < 0.05), PEFR > 200 L/min (OR 17, 95\% CI 1.4-196, p < 0.05) and absence of lung infection (OR 13.5, $95 \%$ CI $1.4-123, \mathrm{p}<0.05)$. The day of onset of respiratory failure and the total dose of atropine required did not predict successful extubation with significance.

Conclusion: Multiple clinical parameters can be used to guide successful extubation following OP-induced respiratory failure.

\section{EFFECT OF CONCOMITANT ATROPINE AND GLYCOPYRROLATE INFUSION IN ORGANOPHOSPHORUS POISONING}

\section{VR Xavier, Girish Thung, Kishore Gnana Sam, Sureshwar Pandey and Kanav Kehra.}

Department of Pharmacy Practice, Manipal College of Pharmaceutical Sciences, Manipal, 576104

Aim: To study the effectiveness of concomitant atropine and glycopyrrolate infusion over atropine infusion in organophosphorus (OP) poisoning.

Methods: A prospective randomized study was carried out among 60 OP-poisoned patients admitted to an emergency department of a tertiary care hospital in south India. All patients admitted with acute OP poisoning were enrolled in the study. They were randomized into a test group and control group of 30 patients each. Patients who received only atropine alone were randomized as the control group and patients who received concomitant glycopyrrolate were enrolled in the test group. All patients were provided $1 \mathrm{~g}$ pralidoxime every 8 hours. The severity was assessed using GCS, APACHE II, and PSS scores at admission. The outcomes were assessed in terms of intermediate syndrome, ventilation period, total dose and duration of atropine, atropine toxicity, incidence of pneumonia, hospitalization period and mortality.

Results: A total of 60 patients were admitted due to OP poisoning during a one-year period. At admission, there were no significant differences in demographic data, time of arrival, initiation of treatment and severity of poisoning. Comparison of the two groups showed that there was a significant improvement of ventilator period in the study group (4.2 days) than the control group (5.4 days). Intermediate syndrome was developed in $10 \%$ of control group and only $2 \%$ of the study group developed intermediate syndrome. The total atropine requirement and duration was reduced in the study population. Atropine-induced CNS toxicity was observed in $40 \%$ of the control group while only $4 \%$ of the study group had CNS toxicity. A total of 30\% of the patients in the control group developed pneumonia versus only $10 \%$ of study group. However, there was no significant difference in mortality rate and number of hospitalization days in both groups.

Conclusion: Glycopyrrolate also has been tried as an alternative for atropine. The major advantage of the drug is it has less effect on the central nervous system when compared with atropine and the combination will be more beneficial, as it reduces the toxicity of atropine on the central nervous system. Addition of glycopyrrolate appears to be a promising intervention in the management of OP poisoning. 


\title{
ASSESSMENT OF AUTONOMIC FUNCTION IN PATIENTS WITH ACUTE ANTICHOLINESTERASE POISONING
}

\author{
SS Jayasinghe ${ }^{a, b}, \mathrm{~K}$ Pathiranac
}

aDepartment of Pharmacology, Faculty of Medicine, University of Ruhuna, Sri Lanka; bSouth Asian Clinical Toxicology Research Collaboration; ' ${ }^{\mathrm{D}}$ Department of Medicine, Faculty of Medicine, University of Ruhuna, Sri Lanka

Objective: The aim of the study was to investigate whether the autonomic nervous system is altered by acute anticholinesterase poisoning.

Method: A cross-sectional study carried out to assess the integrity of the autonomic nervous system in patients with acute anticholinesterase poisoning at discharge. Autonomic function was assessed in 23 patients (6, carbamate, 17, organophosphorus). 16 patients were male and the mean age was 35 (SD 13) years. None of them had diabetes; mean HbA 1 C 5.5\% (SD 0.64). Autonomic neuropathy was assessed by the standard measurement of cardiovascular reflexes (Table 1$)[1,2,3]$. The first three reflect cardiac parasympathetic integrity, while the other two reflect cardiac sympathetic integrity [1].

\begin{tabular}{|c|c|c|c|}
\hline Test & Normal & Borderline & Abnormal \\
\hline $\begin{array}{l}\text { Heart rate response to Valsalva maneuver (Valsalva } \\
\text { ratio-longest } R-R \text { interval after the maneuver } \\
\text { to the shortest } R-R \text { interval during the maneuver) }\end{array}$ & $\geq 1.21$ & $1.11-1.2$ & $\leq 1.10$ \\
\hline $\mathbf{n}=\mathbf{2 2}$ & 19 & 3 & 0 \\
\hline $\begin{array}{l}\text { Heart rate variation during deep breathing } \\
\text { (maximum-minimum heart rate beats } / \mathrm{min} \text { ) }\end{array}$ & $\geq 15$ & $11-14$ & $\leq 10$ \\
\hline $\mathbf{n}=\mathbf{2 2}$ & 10 & 7 & 5 \\
\hline Heart rate response to standing ( $30: 15$ ratio) & $\geq 1.04$ & $1.01-1.03$ & $\leq 1.00$ \\
\hline $\mathbf{n}=\mathbf{2 3}$ & 20 & 3 & \\
\hline $\begin{array}{l}\text { Blood pressure response to standing (fall in systolic } \\
\text { blood pressure } \mathrm{mm} \mathrm{Hg} \text { ) }\end{array}$ & $\leq 10$ & $11-29$ & $\geq 30$ \\
\hline $\mathbf{n}=\mathbf{2 2}$ & 20 & 2 & 0 \\
\hline $\begin{array}{l}\text { Blood pressure response to sustained handgrip } \\
\text { (increase in diastolic blood pressure } \mathbf{m m} \mathbf{~ H g} \text { ) }\end{array}$ & $\geq 16$ & $11-15$ & $\leq 10$ \\
\hline$n=6$ & 6 & 0 & 0 \\
\hline
\end{tabular}

Results: The tests reflecting parasympathetic integrity were normal in 9 (39\%) patients. In 14 (61\%) patients, one or more tests were borderline or abnormal. Blood-pressure response to standing was assessed in 22 patients; 2 (9\%) showed borderline results. 20 patients underwent the assessment of blood-pressure response to sustained handgrip; 6 were able to complete the test; results were within normal.

Conclusions: $61 \%$ of the patients with acute anticholinesterase poisoning had evidence of parasympathetic dysfunction. Although only $9 \%$ of patients showed sympathetic dysfunction, this may be an underestimate since these tests give abnormal results only with severe peripheral sympathetic damage. We intend to study further patients and follow up over time to further define the natural history of autonomic dysfunction due to acute anticholinesterase poisoning.

\section{References:}

1. Ewing DJ, Clarke BF. Diagnosis and management of diabetic autonomic neuropathy. British Medical Journal 1982;285(2):916-918.

2. Giorgetti GM, Tursi A, Lani C, et al. Assessment of autonomic function in untreated adult coeliac disease. World J Gastroenterol 2004;10(18):2715-2718.

3. Michael J Aminoff. Evaluation of the autonomic nervous system. Electrodiagnosis in Clinical Neurology. 5th ed. Philadelphia: Elsevier. 2005:410-417. 


\title{
A PIG MODEL OF DIMETHOATE PESTICIDE POISONING
}

\author{
M Eddleston ${ }^{a, c, d}$, Clutton $E^{b}$
}

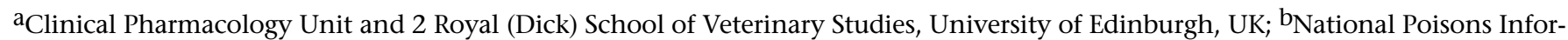
mation Bureau-Edinburgh, Royal Infirmary, Edinburgh, UK; CSouth Asian Clinical Toxicology Research Collaboration, Sri Lanka

Objective: Dimethoate pesticide poisoning is a major clinical problem in rural Asia. Unlike poisoning with other OPs, the majority of dimethoate deaths result from delayed cardiovascular shock after early respiratory failure. The reason for this different clinical presentation is unclear. We set up a pig model of dimethoate poisoning to explore the pathophysiology of this poisoning.

Methods: Gottingen minipigs were anaesthetized before placement of central arterial and venous lines. They were then poisoned with standard agricultural dimethoate (40\% emulsifiable concentrate [EC40]) or dimethoate $25 \%$ active ingredient in ethanol. Atropine, pralidoxime, noradrenalin, and fluids were administered as required. Blood samples were taken for pharmacokinetic/dynamic studies; neuromuscular junction (NMJ) function was assessed by mechanomyography.

Results: $2.5-\mathrm{ml} / \mathrm{kg}$ dimethoate EC40 caused severe hypotension due to peripheral vasodilatation that was similar to human poisoning. High doses of noradrenaline were required to maintain a mean arterial blood pressure above $55 \mathrm{mmHg}$; this was associated with a blood lactate that rose over 10 hours to $15 \mu \mathrm{mol} / \mathrm{L}$. The red cell acetylcholinesterase activity fell to $<20 \%$ of normal by 4 hours; there was minimal response to pralidoxime ( $25 \mu \mathrm{mol} / \mathrm{L}$ ). NMJ function failed by 12 hours. $1.25 \mathrm{ml} / \mathrm{kg}$ dimethoate EC40 caused identical inhibition of red cell acetylcholinesterase and NMJ failure, but no severe hypotension or hyperlactataemia. Unformulated dimethoate active ingredient similarly inhibited red cell acetylcholinesterase but did not cause severe hypotension, hyperlactataemia, or NMJ failure.

Conclusion: This study showed that severe red cell acetylcholinesterase inhibition was not necessarily associated with severe illness. The identical red cell acetylcholinesterase inhibition without clinical illness in pigs administered unformulated dimethoate suggests that the coformulants-solvents (such as cyclohexanone and xylene) and surfactants-may be important. Further studies are needed to determine whether these findings remain true for other OP pesticides and to clarify the mechanisms of cardiovascular shock.

\section{VALIDATION OF THE TESTMATE CHE 460 BEDSIDE KIT IN THE DETERMINATION OF RED BLOOD CELL ACETYLCHOLINESTERASE AND PLASMA CHOLINESTERASE IN ORGANOPHOSPHORUS, CARBAMATE, AND UNKNOWN PESTICIDE POISONING}

\author{
BN Rajapakse, H Thiermann, P Eyer, F Worek, S Bowe, NA Buckley \\ South Asian Clinical Toxicology Research Collaboration (SACTRC)
}

Introduction: Monitoring levels of acetylcholinesterase is useful in the management of OP poisoning, but unfortunately the laboratory facilities for this test are currently unavailable in many parts of the world. Testmate ChE 460 is a bedside testing kit developed in the USA to monitor red blood cell acetylcholinesterase (RBC-AChE) and plasma cholinesterase (PChE) in patients who have had occupational exposure to pesticides. This is the first paper reporting the validation of this testing device in human patients with pesticide toxicity resulting from self poisoning.

Aims: (1) To determine the level of agreement between RBC-AChE and PChE levels measured using the Testmate bedside test when compared with a reference laboratory in patients acutely poisoned by organophosphorus, carbamate, or unknown pesticides. (2) To determine the clinical factors that might lead to a lack of agreement.

Methods: Patients admitted to two general hospitals in Sri Lanka with a history of organophosphorus, carbamate, or unknown pesticide poisoning between September 2007 and April 2008 were recruited, and the RBC-AChE and PChE levels were measured using Testmate ChE. In addition, a duplicate sample was prepared using a previously described method (using dilution and cooling), which was later analyzed at a reference laboratory using the modified Ellman technique.

Results: There were 36 patients in the study, with a total of 182 and 147 paired of results for RBC-AChE and PChE, respectively. Overall, there was good correlation between the Testmate and reference laboratory results (Spearman's correlation coefficients 0.83 and 0.74 for RBC-AChE and PChE, respectively). There was also good agreement between test results for the different clinical categories of RBC-AChE inhibition (normal, mild inhibition, moderate inhibition, and severe inhibition) as reflected by a weighted kappa [w2] of 0.76 (prob $>\mathrm{z}=0.0000$ ). The Bland Altman analysis showed there was a mean positive bias in the testmate result of $1.5 \mathrm{U} / \mathrm{g}$ $\mathrm{Hb}$ (SD, 7.3; 95\% CI, 12.8 to 15.9) for RBC-AChE and a negative bias of $-0.144 \mathrm{U} / \mathrm{L}$ for PChE.

Discussion: There were systematically lower values of AChE recorded in one hospital when compared with results from the other, which may reflect problems with the storage of samples in this centre. One potential factor in differences seen could be related to the quality of Testmate operation as the test was carried out by junior doctors in the study but was designed to be carried out by trained laboratory personnel. 
Conclusion: The Testmate ChE is able to give clinically reliable results in OP, carbamate, and unknown pesticide-poisoned patents when operated by medical personnel in a rural hospital setting, and may have further application in the management of pesticide poisoning and toxicological research.

\title{
EFFECT OF CONTINUOUS PRALIDOXIME INFUSION IN SEVERE METHYLPARATHION POISONING: A CASE SERIES
}

\author{
G Thunga, K Gnana Sam, VR Xavier, S Pandey, K Kehra. \\ Department of Pharmacy Practice, Manipal College of Pharmaceutical Sciences, Manipal 576104
}

Objective: The aim of the present study was to assess whether continuous infusion of pralidoxime can improve the outcome of patients with severe methylparathion poisoning.

Case Series: Six patients were admitted to the emergency centre of a tertiary care hospital of south India, with severe methyl parathion poisoning due to intentional self harm. All the patients were directly admitted to the emergency centre within an average prehospitalization period of $50 \pm 10.6$ minutes. The average age of patients was $28 \pm 6.4$ years and all of them belonged to agricultural group. At initial presentation, all the patients had altered sensorium, along with diaphoresis and salivation. Two of them had skeletal muscle fasciculation and two developed generalized seizures. The baseline severity of poisoning was assessed using clinical severity indices like the Glasgow coma scale (GCS); Poison Severity Scale (PSS) and cholinesterase levels. The mean initial GCS and PSS scores were 7.2 \pm 3.5 and $2.7 \pm 0.6$, respectively, while plasma cholinesterase level was $191.3 \pm 276.5 \mathrm{IU} / \mathrm{L}$. All of them had respiratory depression and hence required mechanical ventilation within 24 hours of admission. After decontamination by gastric lavage, they were administered a bolus dose of $5 \mathrm{mg}$ atropine intravenously initially and then at $1 \mathrm{mg} / \mathrm{hour}$ by continuous infusion till clinical symptoms of poisoning subsided. Dosage was adjusted based on atropinization symptoms like pulse rate or dryness of tongue. Pralidoxime was administered as a continuous intravenous infusion at a rate of $500 \mathrm{mg} / \mathrm{hour}$ after an initial bolus dose of $2 \mathrm{~g}$ (over 30 minutes) initially for 2-3 days and tapered to $250 \mathrm{mg} /$ hour for 2 more days and $125 \mathrm{mg} /$ hour for two more days, with a total duration of 1 week. The average dose of atropine required was $820.8 \pm 1528.9 \mathrm{mg}$, while the average dose of PAM administered was $42 \pm 10 \mathrm{~g}$ for a mean duration of $6.5 \pm 0.5$ days. The average serum level of pralidoxime was $21.33 \pm 5.26 \mathrm{~g} / \mathrm{dl}$ and was not associated with adverse effects. The average ventilation period was $48.2 \pm 12.6$ hours. All six patients successfully recovered, with a mean hospitalization period of $10.2 \pm 2.5$ days.

Discussion: The use of oximes in OP poisoning is still controversial and varies in opinion between physicians with regards to dose, regimen, and duration of treatment. Limited studies are available to prove the clinical benefits of oximes in OP poisoning [1]. The observations of the present study supports that WHO regimen of $30 \mathrm{mg} / \mathrm{kg}$ and $8 \mathrm{mg} / \mathrm{kg} / \mathrm{hour}$ infusion is clinically effective and not associated with adverse effects [2].

Conclusion: Continuous infusion of pralidoxime after initial decontamination improved hospitalization period, clinical outcome, and decreased atropine requirement in severe methyl parathion poisoning.

References:

1. Bairy KL, Vidyasagar S, Sharma A. Controversies in the management of organophosphorus poisoning. Indian Journal of Pharmacology 2007; 139:71-74.

2. Eddleston M, Szinicz L, Eyer P, et al. Oximes in acute organophosphorus pesticide poisoning: a systematic review of clinical trials. Q J Med 2002;95:275-283.

\section{PATTERNS OF BETA-GLUCURONIDASE IN PESTICIDE SELF-POISONING}

\author{
BN Rajapakse, T Sato, F Mohammed, NA Buckley \\ South Asian Clinical Toxicology Research Collaboration (SACTRC)
}

Introduction: Beta-glucuronidase (BG) has been suggested as a more sensitive and rapid biomarker of exposure to suspected organophosphorus and carbamate pesticides.

Methods: Blood samples measuring BG were taken in 33 consenting patients treated for suspected or confirmed anticholinesterase pesticide self-poisoning at 2 hospitals in Sri Lanka. Most patients had moderate symptoms and required treatment with atropine and/or pralidoxime. The majority of patients also had depressed RBC acetylcholinesterase and plasma cholinesterase.

Results: The mean BG value observed was 861.3 IU/dL (IQR, 622-1055; range, 307.6-2154). BG was observed to be higher than the upper limit of normal in $86 \%$ of samples taken. However, there was no consistent temporal pattern after admission. The BG went up in some patients and down in others as they improved over the first few days. There was also not a close relationship to severity between individuals; the highest levels were observed in a patient with only mild poisoning. 
Conclusions: The results we observed are consistent with beta-glucuronidase being a sensitive biomarker of OP exposure. However, its use in the assessment of acute exposures requires further investigation. In particular, it is important to examine for a consistent effect with all anticholinesterases and to gain data on how long levels remain elevated after resolution of clinical effects. It is also important to determine if there are inherited or acquired factors that influence the baseline levels or response to pesticides.

\title{
A PHASE II CLINICAL TRIAL TO ASSESS THE SAFETY OF CLONIDINE IN ACUTE ORGANOPHOSPHATE POISONING
}

\author{
PMS Perera a SF Jayamanna ${ }^{a, d}$, R Hettiarachchia,d, C Abeysinghea,e, H Karunathilaka, ${ }^{a}$, , AH Dawson a,b, NA \\ Buckley $a, b, c$ \\ aSouth Asian Clinical Toxicology Research Collaboration, Faculty of Medicine, University of Peradeniya, Sri Lanka; ${ }^{b}$ Australian \\ National University Medical School; CPrince of Wales Hospital Clinical School, University of NSW, Australia; dPolonnaruwa \\ General Hospital, Sri Lanka; ${ }^{e}$ Chilaw General Hospital, Sri Lanka
}

Objective: To determine the safety of clonidine given as an antidote in adult patients presenting with signs or symptoms of acute organophosphate ingestion.

Methodology: This study was a dose finding, open-label, multicentre, phase II trial. Forty-eight patients with acute organophosphate poisoning were randomized to receive either clonidine or placebo: 4 to receive placebo and 12 to receive clonidine at each dose level. The first dose level was an initial loading dose of $0.15 \mathrm{mg}$ followed by an infusion of $0.5 \mathrm{mg}$ of clonidine over 24 hours. The initial loading dose was increased to $0.3 \mathrm{mg}, 0.45$, and $0.6 \mathrm{mg}$. In the subsequent dosing levels, however, the infusion rate remained the same.

Findings: The baseline characteristics of both groups were similar. The trial was stopped after completion of the 3rd dosing level. At the 1st and 2nd dosing levels, there were no reported adverse events. At the 3rd dosing level, 5 patients (42\%) developed significant hypotension during clonidine treatment. There were no statistical differences in ventilation rate, pre- and post-GCS, and mortality rates over all levels.

Conclusions: Our findings suggest that clonidine is well tolerated at the two lowest dosing levels; higher doses are associated with a high incidence of hypotension requiring intervention. These initial findings support doing further studies to characterize the efficacy profile of clonidine as an alternative antidote.

\section{RELATIONSHIP BETWEEN THE SERUM CHLORPYRIFOS LEVEL AND THE DEVELOPMENT OF INTERMEDIATE SYNDROME FOLLOWING ACUTE ORGANOPHOSPHATE POISONING}

\author{
P Jayawardane, P Eyer, N Senanayake, N Buckley, A. Dawson \\ South Asian Clinical Toxicology Research Collaboration
}

Introduction: We previously reported that acetylcholinesterase inhibition only partially explains the development of intermediate syndrome (IMS) spectrum disorder [1,2]. The objective of this study was to assess the association between serum chlorpyrifos and the development of the IMS spectrum disorder.

Methods: $2 \mathrm{ml}$ of blood was collected with an EDTA tube and centrifuged promptly, and plasma was separated and frozen at $-200^{\circ} \mathrm{C}$ until analysis in 43 symptomatic acute chlorpyrifos patients on admission, 1 hour, 4 hours, 12 hours, and 24 hours following admission, and daily thereafter. Serum chlorpyrifos levels were assessed using high-performance liquid chromatography. To represent the amount of circulating chlorpyrifos level during first 24 hours and 48 hours following admission, area under the curve (AUC) was calculated by plotting the serum chlorpyrifos concentration against time. The Mann Whitney U (MWU) test was used to compare the groups.

Results: The 24-hour and 48-hour AUC for serum chlorpyrifos were calculated in 43 and 40 patients, respectively. There was a significant difference between the 2 groups in both the 24-hour and 48-hour AUC of serum chlorpyrifos (Table 1).

Table 1: Influence of the Poison Load (Plasma Chlorpyrifos AUC) on the Development of IMS Spectrum Disorder

\begin{tabular}{lccc}
\hline & \multicolumn{1}{c}{ IMS spectrum } & Non-IMS & P Value \\
\hline $\begin{array}{l}\text { 24-hour AUC } \\
\left.\text { (Median } \mu M^{*} \mathrm{~h}[\mathrm{IQR}]\right)\end{array}$ & $35.64(14.00-52.42), \mathrm{n}=25$ & $15.42(3.95-27.51), \mathrm{n}=18$ & 0.0159 \\
$\begin{array}{l}\text { 48-hour AUC } \\
\left.\text { (Median } \mu \mathrm{M}^{*} \mathrm{~h}[\mathrm{IQR}]\right)\end{array}$ & $55.45(29.78-80.73), \mathrm{n}=22$ & $21.43(5.1-37.58), \mathrm{n}=18$ & 0.0027 \\
\hline
\end{tabular}


Conclusions: The development of IMS spectrum disorder is associated with higher circulating chlorpyrifos concentrations in blood as well as more severe acetylcholinesterase inhibition.

References:

1. Jayawardane P, Dawson A, Buckley N, Senanayake N, Eyer P. Red blood cell acetylcholinesterase inhibition and the intermediate syndrome Clinical Toxicology 2008;46:396.

2. Jayawardane P, Dawson A, Weerasinghe V H, Karalliedde L, Buckley N, Senanayake N. The spectrum of intermediate syndrome following acute OP poisoning: A prospective cohort study from Sri Lanka. PLoS Med 2008;5(7):1143-1152.

\title{
BIOSCAVENGER THERAPY IN ORGANOPHOSPHATE POISONING (BIOSTOP)- A PILOT STUDY
}

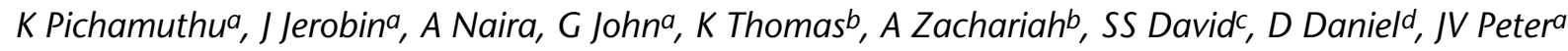

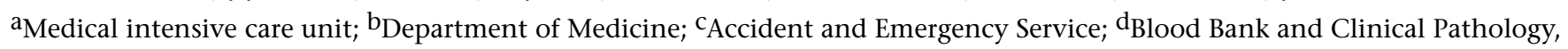 \\ Christian Medical College Hospital, Vellore, India
}

Introduction: Accidental and suicidal poisoning with organophosphate compounds continue to be an important reason for intensive care admissions in developing countries. Traditional approaches of treating with oximes have had limited success. Fresh frozen plasma (FFP) as a bioscavenger has been described as resulting in dramatic reductions in mortality and incidence of intermediate syndrome [1]. While this has been attributed to the mopping up effect of butryl- cholinesterase in the FFP, others have argued the role of albumin in adsorbing the organophosphate [2].

Design: Pilot open-label, 3-arm, randomized controlled study.

Methods: 60 consenting patients with organophosphate poisoning were randomized to receive either FFP (8 bags over 3 days), $20 \%$ human albumin (400 $\mathrm{ml}$ over 3 days), or saline (2000 $\mathrm{ml}$ over 3 days) in addition to atropinisation and supportive care. Oximes were not used.

Results: The interventions did not affect the need for ventilation (73.7\% vs. 75\% vs. 73.7\% in FFP, albumin, and saline arms) or prevent delayed intubations ( $>6$ hours after randomization) (5.3\% vs. 5\% vs. 5.3\%). There were no statistically significant (all $p$ values $>0.1$ ) differences in mean $( \pm$ SE) total atropine required in the first 3 days $(536 \pm 132$ vs. $361 \pm 125$ vs. $789 \pm 334)$, duration of ventilation $(10.0 \pm 2.0$ vs. $7.0 \pm 1.4$ vs. $7.5 \pm 1.5$ days $)$ or length of hospital stay $(11.94 \pm 2.2$ vs. $9.8 \pm 1.4$ vs. $9.8 \pm 1.6$ days $)$. Although similar rates of mortality were observed in all arms (16.7\% vs. 20\% vs. 15.8\%), there was a trend towards higher incidence of clinically definable intermediate syndrome in patients administered FFP (53.3\% vs. 25\% vs. $21.4 \%$ ).

Conclusions: Although the small number of patients studied limits interpretation, fresh frozen plasma and albumin do not seem to confer any significant clinical advantage to organophosphate-poisoned patients in terms of mortality or morbidity.

References:

1. Guven M, Sungur M, Eser B, et al. The effects of fresh frozen plasma on cholinesterase levels and outcomes in patients with organophosphate poisoning. J Toxicol/Clin Toxicol 2004;42(5):617-623.

2. Fulton JA, Bouchard NC, Becker ML, et al. FFP in organophosphate poisoning: what's the secret ingredient? Clin Toxicol (Phila) $2005 ; 43(3): 215$.

\section{AN IN VITRO STUDY TO DETERMINE THE ABILITY OF PLASMA PROTEINS AND ALBUMIN TO SCAVENGE ORGANOPHOSPHATE COMPOUNDS}

\author{
SJ Priyadarshinia, A Oommen ${ }^{b}$, A Ramachandrana \\ aWellcome Trust Research Laboratory, Department of Gastrointestinal Sciences; ${ }^{b}$ Department of Neurological Sciences, Christian \\ Medical College, Vellore, India
}

Introduction: Organophosphate pesticide poisoning is a common method of suicide in the developing world. Treatment with oximes is controversial; they might benefit only patients poisoned by specific organophosphates or patients with moderate poisoning. New treatments, such as the use of fresh frozen plasma or albumin to scavenge organophosphates, have been suggested. The aim of this study was to determine in vitro if components of fresh frozen plasma, especially albumin, bind organophosphate compounds and thus help in scavenging these compounds in poisoned patients.

Methods: Butrylcholinesterase was purified from serum by ion exchange chromatography. Inhibition of butrylcholinesterase by increasing concentrations $(0-1.5 \mu \mathrm{M})$ of monocrotophos was used to generate an inhibition profile to determine free monocrotophos levels in test samples. For scavenging studies, albumin $(16 \mathrm{~g} \%)$ was incubated with monocrotophos $(40 \mu \mathrm{M})$ for 1 hour at $37^{\circ} \mathrm{C}$, the albumin removed by blue sepharose affinity, and monocrotophos levels determined in the remaining solution by addition to pure 
butrylcholinesterase and assay of enzyme activity. Similarly, plasma was incubated with monocrotophos (40 $\mu \mathrm{M})$, albumin removed and free monocrotophos levels estimated.

Results: Butrylcholinesterase was purified 298-fold from serum and exhibited a specific activity of 4.5 U/mg protein. Monocrotophos inhibited butrylcholinesterase in a dose-dependent manner with $1.5 \mu \mathrm{M}$ monocrotophos inhibiting butrylcholinesterase by $68 \%$. Albumin (16 g \%) bound approximately $40 \mu \mathrm{M}$ monocrotophos and albumin-bound monocrotophos could be separated from free, unbound monocrotophos. Monocrotophos bound to plasma containing $5 \mathrm{~g} \%$ albumin, plasma free of albumin bound to approximately $40 \mu \mathrm{M}$ monocrotophos.

Conclusion: The inhibition of butrylcholinesterase offers a functional assay to detect organophosphate levels. Albumin exhibits saturating binding of monocrotophos, and monocrotophos bound to albumin can be separated from unbound monocrotophos. Monocrotophos binds not only to albumin but also to other components of plasma. In vitro, plasma and albumin exhibit the ability to scavenge organophosphates.

\title{
SERIAL MONITORING OF ACETYL CHOLINESTERASE AND BUTYRYL CHOLINESTERASE LEVELS IN PATIENTS WITH ACUTE ORGANOPHOSPHORUS POISONING
}

\author{
A Jose, JJ Fleming, R Selvakumar \\ Department of Clinical Biochemistry, Christian Medical College, Vellore 632 004, Tamil Nadu, India
}

Objective: This study was to determine if changes in enzyme activity of butyrlcholinesterase (BChE) and red cell acetylcholinesterase (AChE) [1] could be used to follow the clinical progress of the patients with acute OP poisoning and their response to treatment.

Methods: Patients were enrolled if admission BChE was $<1000 \mathrm{U} / \mathrm{L}$ and were randomised into 3 treatment arms: albumin $(\mathrm{n}=19)$ who received $20 \%$ albumin; fresh frozen plasma (FFP) $(\mathrm{n}=18)$; and saline placebo $(\mathrm{n}=17)$. Specimens were taken at admission, second and third day after admission, and at discharge.

Results: Fifty-four patients with OP self-poisoning were enrolled in this study during 2007 to 2008 . The patient cohort consisted of 44 males and 10 females. The mean age was 30.02 \pm 13.01 years. The median duration of hospitalization was 7 days (2-41 days). Nine patients expired during treatment. Both cholinesterases were highly inhibited on day 1 in all the 3 treatment arms. The median AChE values at admission were 20.5

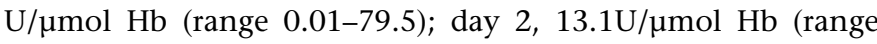
0.01-77.1); day 3, $18.5 \mathrm{U} / \mu \mathrm{mol} \mathrm{Hb}$ (range 0.01-79.8); discharge, $19.6 \mathrm{U} / \mu \mathrm{mol} \mathrm{Hb}$ (range 0.01-49.7), respectively. Reference values in 21 subjects were median 106.6 U/ $\mu \mathrm{mol} \mathrm{Hb}$ (range 87.7-185.4). The serial changes in BChE activity are shown in Figure 1. Reference values for BChE were median 7922 (range 4902-11924 U/L).

Conclusions: Recovery of BChE occurred in the FFP arm, but was much slower in the saline and albumin arm. BChE present in the FFP may have been responsible. AChE values were depressed on day 1 and did not recover in any group by discharge. They

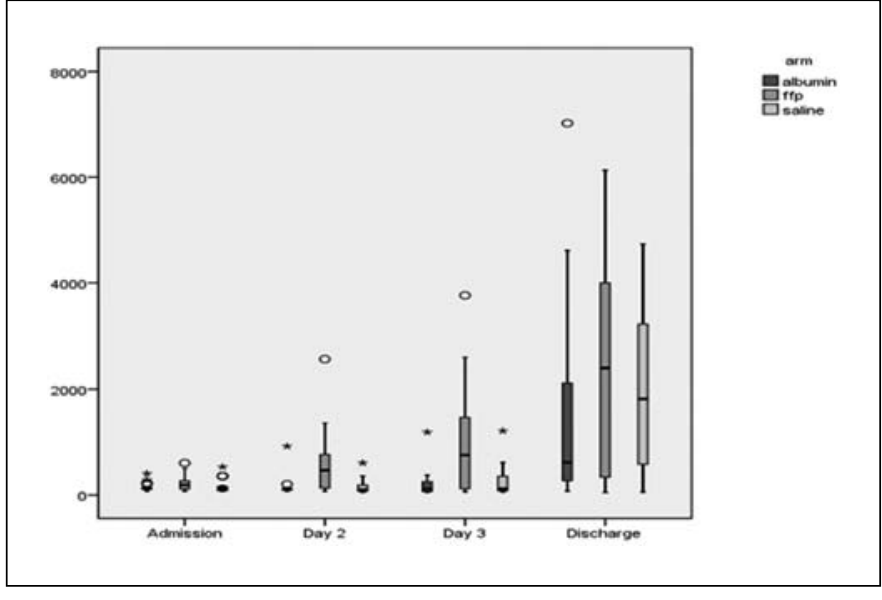

Figure 1: Serial monitoring of BChE values. could not be used to monitor clinical progress of the patients.

\section{Reference:}

1. Worek F, Mast U, Kiderlen D et al. Improved determination of acetylcholinesterase activity in human whole blood. Clin Chim Acta 1999;288:73-90. 